\title{
Layout Calculations Related to Product Insourcing
}

\author{
Michal Šimon \& Tomáš Broum
}
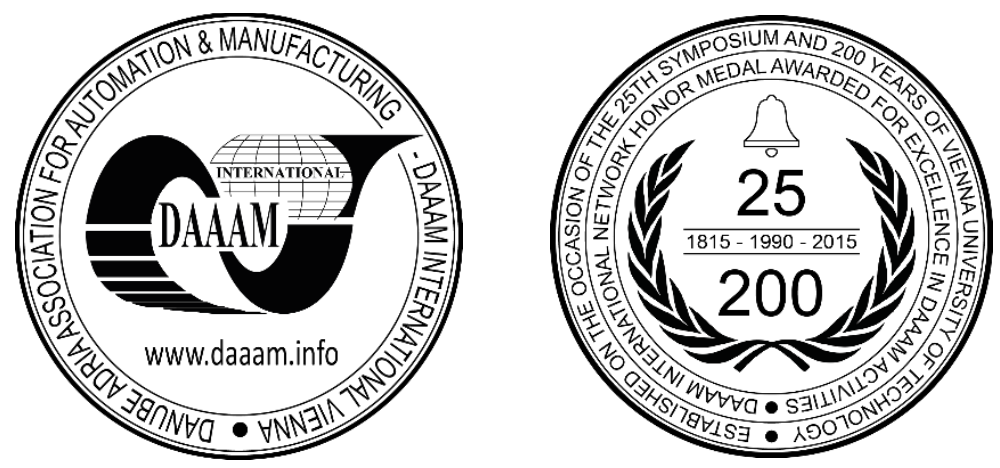

This Publication has to be referred as: Simon, M[ichal] \& Broum, T[omas] (2018). Layout Calculations Related to Product Insourcing, Proceedings of the 29th DAAAM International Symposium, pp.0312-0318, B. Katalinic (Ed.), Published by DAAAM International, ISBN 978-3-902734-20-4, ISSN 1726-9679, Vienna, Austria DOI: $10.2507 / 29$ th.daaam.proceedings.045

\begin{abstract}
The paper focuses on the examination of the product - layout connection. The main focus is on the impact of product complexity and product quantity on the final layout of an industrial plant. The examination is based on a practical case study of product insourcing to an industrial company. The product used in this case study is from the automotive industry - a front seat armrest. The product involves 3 production groups. Each production group has a different complexity and production quantity. A comparison of the layout impacts of the different production groups and a comparison with the total layout (where all the production groups are presented) is the main subject of this paper. The paper also describes the calculation steps during the case study. This can give practical instructions that can be followed towards creating a successful layout design for product insourcing.
\end{abstract}

Keywords: product insourcing; layout calculations; case study; automotive industry

\section{Introduction}

In the current competitive business world, when the supply is higher than demand, characteristics of speed, efficiency and quality of processes are very important in production systems. Products are generally needed of the exact quality, in the shortest term and for the lowest possible price. Regarding the product itself, its costs are determined mostly in the design phase. Modern methods for production system optimisation can influence the situation in a positive way [1],[2],[3], but still the design phase is the most important of the phases related to product costs. [4] The design phase of the product and its related production system consists of a few parts. An important part of the design phase necessary for achieving an optimized production system is concentration on its layout. This paper focuses on the examination of the productlayout connection. The main focus is on the impact of the product complexity and product quantity on the final layout of the industrial plant. The examination is based on a practical case study of product insourcing to an industrial company. The product used in this case study is from the automotive industry - a front seat armrest. The product involves 3 production groups. Each production group has a different complexity and production quantity. The complexity is based on the number of machine types involved in the production by a specific production group. The quantity is based on the number of armrests produced in one year. The layout is quantified by the total square metres occupied. The square metres include the production and support (necessary production logistics) area. The input data are shown in Table 1. A comparison of the layout impacts of the different production groups and a comparison with the total layout (where all the production groups are presented) is the main subject of this paper. 


\begin{tabular}{|c|c|c|}
\hline Production group & Quantity (pcs / year) & Complexity (No. of machine types) \\
\hline Production group 1 & 37399 & 4 \\
\hline Production group 2 & 580156 & 5 \\
\hline Production group 3 & 234639 & 8 \\
\hline Total layout (1+2+3) & 852194 & 8 \\
\hline
\end{tabular}

Table 1. Input data

The case study is calculated in the next part of the paper. It shows the steps for calculating the basic layout data. Only a few examples of the calculation are shown, as a complete, detailed calculation of each machine type for each production group would significantly exceed the intended length of this paper. Even with this simplification the case study can still provide practical instructions for creating a successful layout design for product insourcing. For complete manufacturing layout design the information from the paper by Srajer, V. \& Kleinova, J. [5] or Srajer, V.; Broum, T. \& Kleinova, J.[6] can be used.

\section{Case study}

The company in the case study outsources the production of a car component - a front seat armrest. The intention is to make the product by insourcing - to produce the product internally. The case study shows the layout calculation in the following steps:

- Product definition, production process information

- Surface calculations

- Calculation of production quantity

- Detailed calculation of support surface

- Layout proposal

\subsection{Product definition, production process information}

Firstly, the product has to be defined. This step contains three parts: product information, machine information (with a basic link to the process) and the technological process of each product.

All the specifications of different types of relevant product need to be collected and sorted. For armrests they are: the type of cover, the colour of cover and the technology of production related to each type. An example of the specification is shown in Table 2.

\begin{tabular}{|c|c|c|c|}
\hline Product name & $\begin{array}{c}\text { Product } \\
\text { code }\end{array}$ & Product variant (type, colour) & Cover \\
\hline \multirow{2}{*}{ Product A } & AABB & Clip UNI Black & Fabric \\
\cline { 2 - 4 } & AABC & UNI Black & Leather \\
\hline \multirow{2}{*}{ Product B } & BBAB & PERF Black & Leatherette \\
\cline { 2 - 4 } & BBAC & PERF Canberra beige & Leatherette \\
\hline
\end{tabular}

Table 2. Product information

This step concentrates on the creation of a basic list of process operations and a list of machines needed to be used for insourcing the process. The list of operations is based on the originally defined outsourced process with adjustment from the company's technological department. An example of the list of process operations is shown in Table 3.

\begin{tabular}{|c|c|}
\hline No. of operation & Name of operation \\
\hline 0 & PUR \\
\hline 1 & Cutting of foam \\
\hline 2 & Gluing of foam \\
\hline
\end{tabular}

Table 3. Process operation information 
The list of machines contains not only the specifications of the machines: length, width, supplier and number of machines of a specific type needed, but also information about the operations of each machine. The number of machines is based on the originally defined outsourced process. An example of a list of machines is shown in Table 4.

\begin{tabular}{|c|c|c|c|c|c|c|}
\hline Name of machine & Operation & No. of machines & Width (m) & Length (m) & Supplier & Symbol \\
\hline CUTTER 1 & $1,4,5$ & 2 & 4.57 & 2.98 & ACME & A \\
\hline GLUING Machine 1 & 2 & 1 & 1.35 & 0.72 & ACME & B \\
\hline
\end{tabular}

Table 4. Machine information

The last part of step 2.1 is the list of technological processes of each product containing the operation times and types of machines needed for each operation. An example is shown in Table 5. In the second part of the table, the symbol of the machine for each product is linked to a specific operation in the first, upper part of the table.

\begin{tabular}{|c|c|c|c|c|c|c|c|c|c|c|c|c|c|}
\hline Technological process & & \multicolumn{12}{|c|}{ Operation (seconds) } \\
\hline Product A & Quantity (pcs) & $\mathbf{0}$ & 1 & 2 & 3 & 4 & 5 & 6 & 7 & 3 & 9 & 10 & $11 \mathbf{a}$ \\
\hline $\mathrm{AABB}$ & 15864 & 0.45 & - & - & - & 0.064 & - & - & - & - & - & 0.94 & 0.94 \\
\hline $\mathrm{AABC}$ & 71562 & 0.45 & - & - & - & - & 0.064 & - & - & - & - & 0.94 & 0.94 \\
\hline
\end{tabular}

\begin{tabular}{|c|c|c|c|c|c|c|c|c|c|c|c|c|c|}
\hline Machines & \multicolumn{1}{|c|}{} \\
\hline AABB & & & & & A & & & & & E & F \\
\hline AABC & & & & & & A & & & & E & F \\
\hline
\end{tabular}

Table 5. Technological process

The lists were created on the basis of the actual production process that is outsourced. Original outsourcing of the production was done in close cooperation with the outsourcing company, so the company with insourcing intentions had access to the required information sources.

\subsection{Surface calculations}

This step of the case study concentrates on calculating the layout surfaces related to the insourced product. The following values need to be calculated:

1. $\mathrm{S}_{\mathrm{z}} \quad$ Machine specific area $\left(\mathrm{m}^{2}\right)$

2. $\mathrm{S}_{\mathrm{m}}$ Machine area $\left(\mathrm{m}^{2}\right)$

3. $\mathrm{S}_{\mathrm{v}}$ Production area $\left(\mathrm{m}^{2}\right)$

4. $\mathrm{S}_{\mathrm{p}}$ Support area $\left(\mathrm{m}^{2}\right)$

5. $\mathrm{S}_{\mathrm{c}}$ Operational area $\left(\mathrm{m}^{2}\right)$

The values are calculated as follows:

1. Machine specific area $S_{Z}\left(\mathrm{~m}^{2}\right)$ - Surface needed for individual machine to be placed.

$$
S_{Z}=\mathrm{l} \times \mathrm{w}
$$

1 - length of machine $(\mathrm{m})$

$\mathrm{w}$ - width of machine $(\mathrm{m})$

2. Machine area $S_{m}\left(m^{2}\right)$ - Surface of machine area increased by the safety and production process conditions.

$$
S_{m}=S_{Z} \times \mathrm{K}
$$

$\mathrm{K}$ - Coefficient reflecting safety and production process conditions 


\begin{tabular}{|c|c|}
\hline Machine specific area (m2) & Coefficient K (-) \\
\hline $12-16$ & 2.5 \\
\hline $4-12$ & 3 \\
\hline $2-4$ & 4 \\
\hline $1-2$ & 4.5 \\
\hline $0.5-1$ & 5 \\
\hline$<0.5$ & 6 \\
\hline
\end{tabular}

Table 6. Coefficient K

3. Production area $\mathrm{Sv}\left(\mathrm{m}^{2}\right)$ - Sum of individual machine areas related to one type of machine.

$$
S_{v}=S_{m} \times \mathrm{n}
$$

$\mathrm{n}$ - count of specific type of machine

4. Support area $\mathrm{Sp}\left(\mathrm{m}^{2}\right)$ - Surface needed for input/output material.

$$
S_{p}=S_{v} \times k_{p}
$$

$\mathrm{kp}$ - Coefficient related to calculation surface of support area $(0.4-0.6)$

This is a preliminary calculation of the Support area. A more detailed one is described in step 2.4 of the paper.

5. Operational area $\mathrm{Sc}\left(\mathrm{m}^{2}\right)$ - Surface given by the sum of the production and support area

$$
S_{c}=S_{v}+S_{p}
$$

\begin{tabular}{|c|c|c|c|}
\hline Machine specific area & 13.62 & $\mathrm{~m}^{2}$ & Coeff. K \\
\hline Machine area & 34.05 & $\mathrm{~m}^{2}$ & Coeff. kp \\
\hline Production area & 68.09 & $\mathrm{~m}^{2}$ & \\
\hline Support area & 34.05 & $\mathrm{~m}^{2}$ & \\
\hline Operational area & 102.14 & $\mathrm{~m}^{2}$ & \\
\hline
\end{tabular}

An example of surface calculation results related to a specific type of machine is shown in Table 7.

\begin{tabular}{|c|c|c|c|c|c|c|}
\hline Name of machine & Operation & No. & Width $(\mathbf{m})$ & Lenght $(\mathbf{m})$ & Supplier & Symbol \\
\hline CUTTER 1 & $1,4,5$ & 2 & 4.57 & 2.98 & ACME & A \\
\hline
\end{tabular}

Table 7. Example of surface calculation results related to specific type of machine

The result of this surface calculation step is a list of surfaces related to each specific type of machine.

\subsection{Calculation of production quantity}

This step of the case study concentrates on calculating production quantity per shift on each individual type of machine.

$$
Q_{s t}=\frac{Q}{P_{d} \times P_{s}}
$$

Q $\quad$ - Total number of production quantity per shift (pcs / shift)

Q - Produced quantity per year (pcs / year)

$\mathrm{P}_{\mathrm{d}} \quad$ - No. of working days per year (days / year)

Ps - Shift pattern related to machine/workplace (shift)

Example of the production quantity calculation results related to a specific type of machine is shown in Table 8 . 


\begin{tabular}{|c|c|c|c|c|}
\hline Name of machine & Operation & No. & Supplier & Symbol \\
\hline CUTTER 1 & $1,4,5$ & 2 & ACME & A \\
\hline OPERATION 1 & \multicolumn{3}{|c|}{ OPERATION 4,5 } \\
\hline Q (pcs / year) & 85144 & Q (pcs / year) & 87426 \\
\hline Pd (days / year) & 251 & & 174.2 \\
\hline Ps (shift) & 2 & Qst (pcs / shift) & 87.1 \\
\hline Qst (pcs / shift) & 169.6 & Qst per 1 machine (pcs / shift) & \\
\hline Qst per 1 machine (pcs / shift) & 84.8 &
\end{tabular}

Table 8. Example of the production quantity calculation results related to specific type of machine

The result of this calculation step is a list of production quantity calculation data for each specific type of machine.

\subsection{Detailed calculation of support surface}

A detailed calculation of the support surface can be done if the input and output materials with packaging details are specified for the operations. If the details are available, then the following calculation is recommended. The calculation is shown using the specific example of operation No. 1. Operation No.1. - Output material related to operation 1 has to be packed in KLT packaging with specification in Table 9. No. of packaging (KLTs) needed can be calculated using the following formula:

$$
P_{Q}=\frac{Q_{s t}}{B_{Q}}
$$

$\mathrm{P}_{\mathrm{Q}} \quad$ - No. of packaging needed (pcs)

$\mathrm{B}_{\mathrm{Q}} \quad$ - Box Quantity (pcs / box)

$\mathrm{Q}_{\mathrm{st}} \quad$ - Total production quantity per shift (pcs / shift)

Output material - OPERATION 1

\begin{tabular}{|c|c|c|c|c|c|}
\hline Material spec. & Packaging type & $\begin{array}{c}\text { BQ - Box Quantity } \\
\text { (pcs /box) }\end{array}$ & $\begin{array}{c}\text { Length } \\
\text { (mm) }\end{array}$ & Width (mm) & $\begin{array}{c}\text { Height } \\
\text { (mm) }\end{array}$ \\
\hline Cut foam & KLT & 100 & 600 & 400 & 297 \\
\hline
\end{tabular}

\begin{tabular}{|c|c|c|c|c|}
\hline Surface - KLT & 240000 & $\mathrm{~mm}^{2}$ & 0.24 & $\mathrm{~m}^{2}$ \\
\hline P $_{\mathbf{Q}}$ - No. of packaging & 1.70 & $\mathrm{pcs}$ & $\mathbf{2}$ & pcs rounded \\
\hline Total area needed & 480000 & $\mathrm{~mm}^{2}$ & 0.48 & $\mathrm{~m}^{2}$ \\
\hline
\end{tabular}

Table 9. Example of the output material related to operation 1

So the output material needs 2 KLTs with surface demand of $0.48 \mathrm{~m}^{2}$. Input material calculation can be done in a similar way. Also if the specific racks for packaging are available, then the total surface can be adjusted according to the rack details. An updated list of surfaces related to each specific type of machine is the result of this support surface calculation step.

\subsection{Layout design}

The layout can be designed on the basis of the surface calculation list. The technological process and the rules of layout creation need to respected. Software tools are recommended for layout creation.

\section{Results}

Based on the input data - shown in Table 1, the calculations of operational areas of different production groups together with total layout calculation were made. Production group 1 is specific, with a low number of produced products per year together with low complexity, and only four types of machine are needed for its production. Production group 2 has, on the other hand, a high quantity with still quite low complexity, and five types of machine are needed. Production group 3 can be characterized with a medium number in terms of quantity, but a high complexity of eight machines needed. For comparison, the total layout consisting of all the production groups is included. 
It has high number of parts - a summarization of all the production groups and high complexity of eight types of machines. The results containing the final operational areas are shown in Table 10.

\begin{tabular}{|c|c|c|c|}
\hline Production group & $\begin{array}{c}\text { Quantity } \\
\text { (pcs / year) }\end{array}$ & $\begin{array}{c}\text { Complexity } \\
\text { (No. of machine types) }\end{array}$ & $\begin{array}{c}\text { Operational area } \\
\left(\mathbf{m}^{\mathbf{2}}\right)\end{array}$ \\
\hline Production group 1 & 37399 & 4 & $\mathbf{1 4 4 . 4}$ \\
\hline Production group 2 & 580156 & 5 & $\mathbf{2 6 9 . 9}$ \\
\hline Production group 3 & 234639 & 8 & $\mathbf{2 1 4 . 0}$ \\
\hline Total layout (1+2+3) & 852194 & 8 & $\mathbf{3 0 9 . 2}$ \\
\hline
\end{tabular}

Table 10. Results - absolute values

More interesting than the absolute values shown in Table 10 are the relative values that can be found in Table 11.

\begin{tabular}{|c|c|c|c|}
\hline Production group & $\begin{array}{c}\text { Quantity } \\
(\boldsymbol{\%})\end{array}$ & $\begin{array}{c}\text { Complexity } \\
(\boldsymbol{\%}-\mathbf{N o} \text { of machine types })\end{array}$ & $\begin{array}{c}\text { Operational area } \\
(\%)\end{array}$ \\
\hline Production group 1 & 4.39 & 50.00 & $\mathbf{4 6 . 7 1}$ \\
\hline Production group 2 & 68.08 & 62.50 & $\mathbf{8 7 . 2 7}$ \\
\hline Production group 3 & 27.53 & 100.00 & $\mathbf{6 9 . 2 0}$ \\
\hline Total layout $(1+2+3)$ & 100.00 & 100.00 & $\mathbf{1 0 0 . 0 0}$ \\
\hline
\end{tabular}

Table 11. Results - relative values

Results related to production group number 1 can be interpreted in a way that even with the very low quantity the impact of the complexity makes the layout almost half of the total one. It can also be visible in comparison with production group 2, which has more than fifteen times higher quantity and little increase in complexity that results in an operational area that is almost twice as big. In comparison with production group 3, the more than six times higher quantity and two times higher complexity leads to 1.5 times higher operational area. The reason for this "space inefficiency" (the relation between the produced quantity and the operational area) is that specific machines are needed for production and they need the area anyway, even if they are not fully used - so in this case their capacity has low usage.

Results related to production group number 2 can be interpreted in a way that this production group with high quantity and quite low complexity has much more space efficient results. The machines' capacities are much more utilized than in the other production groups, resulting in the highest "space efficiency". So it could be assumed that the higher the quantity and the lower the complexity, then the space is used more efficiently (the relation between the produced quantity and operational area), regarding the data in this specific case.

Related to production group 3, even with the high complexity and middle quantity, the operational area is much more efficiently used. In comparison with production group number 1, it can be seen that the higher quantity makes sensitivity to complexity lower.

On the basis of these results, it can be assumed that the operational area of production with very low quantity is significantly influenced by the process complexity. Higher quantity makes sensitivity to complexity in operational area lower. And the last point is that the higher the quantity is and the lower the complexity is, then the operational area can be used much more efficiently (efficiency - relation between produced quantity and operational area). If the question is whether or not to implement the insourcing of production group 1, there would be a positive answer only in special cases (high profit luxury products, no other option to outsource the product...). Production group 2 is much more promising, and production group 3 is mid-way depending on the costs and earning relation.

The limitation of the research that the author is aware of is the fact that only one case study in one particular area of industry was examined. To precise the outputs more cases need to be examined. Increasing the number of case studies involved is also one of the areas that is planned to be concentrated on in the future.

\section{Conclusion}

The paper focuses on the examination of the product - layout connection. The assumption in the paper is that the product is already designed. If it is necessary to carry out product design, there are many methods and approaches to support this product life cycle phase, such as the Theory of Technical Systems, Value analysis, etc. The layout design itself is an important part of the product and its production system design phase. The layout influences many important conditions such as production supply and other internal logistics processes. 
The initial situation of examining the subject of the paper was that when the research of the available literature by author was done, there was not found satisfactory answer of the impact of the product quantity and product complexity to the layout of the industrial plant. Description of the impact is the main focus of the paper. The results of the paper are based on a case study that was done in a real company. On the basis of the results, it can be assumed that the operational area of a production group with very low quantity is significantly influenced by the process complexity. Higher quantity makes sensitivity to complexity lower for the operational area. Also, it has to be mentioned that the higher the quantity is and the lower the complexity is - then the space can be used much more efficiently (efficiency - relation between produced quantity and operational area).

Future research plans related to topic described in the paper are concentrated in two areas. First area is concentration on increasing the number of parameters related to the layout area of industrial plant. For example the one that is promising is the capacity of the machines that shows the influence in the current paper also. Second area of potential future research is the evaluation of the impact of the increase number of examined case studies. That could be in automotive industry to precise the output of current research or other industry areas with examination of differences to current research outputs.

\section{Acknowledgments}

This paper was created with the subsidy of the project: SGS-2018-031 under the Internal Grant Agency of the University of West Bohemia: 'Optimizing the parameters of a sustainable production system'.

\section{References}

[1] Kamaryt, T. \& Kleinova, J. (2016). Overall handling equipment efficiency and maintenance systems, IEEE International Conference on Industrial Engineering and Engineering Management, ISSN: 21573611, ISBN: 978146738066-9, pp 838-842, Published by IEEE Computer Society, Singapore, DOI: 10.1109/IEEM.2015.7385766

[2] Poór, P. (2014). Strengthening of boundary processes in a company using specific computer-aided facility management software, SAMI 2014 - IEEE 12th International Symposium on Applied Machine Intelligence and Informatics, Proceedings 2014, ISBN: 978-147993442-3, pp 257-261, Published by IEEE Computer Society, Herl'any; Slovakia, DOI: 10.1109/SAMI.2014.6822418

[3] Poór, P. \& Kuchtová, N. (2014). Methodology for selecting an appropriate module package for a computer aided facility management system in production company, Vision 2020: Sustainable Growth, Economic Development, and Global Competitiveness - Proceedings of the 23rd International Business Information Management Association Conference, IBIMA 2014, ISBN: 978-098604192-1, pp 1058-1067, Published by International Business Information Management Association, IBIMA, Valencia; Spain

[4] Broum, T.; Dvorak, J. \& Kleinova, J. (2011). Value Optimization and Risks Elimination of Product, Annals of DAAAM for 2011 \& Proceedings of the 22nd International DAAAM Symposium, ISSN 1726-9679, ISBN 978-3901509-83-4, Editor B[ranko] Katalinic, pp 0757-0758, Published by DAAAM International, Vienna, Austria,

[5] Srajer, V. \& Kleinova, J. (2011). Effective manufacturing layout as a condition of economy of production, Annals of DAAAM and Proceedings of the International DAAAM Symposium 2011, ISSN 17269679, ISBN: 978390150983-4, Editor B[ranko] Katalinic, pp 525-526, Published by DAAAM International, Vienna, Austria,

[6] Srajer, V.; Broum, T. \& Kleinova, J. (2011). Design of the spatial arrangement of a production system using value analysis, Creating Global Competitive Economies: A 360-Degree Approach - Proceedings of the 17th International Business Information Management Association Conference, IBIMA 2011, ISBN: 978-098214896-9, pp 1051-1056, Published by International Business Information Management Association, IBIMA, Milan; Italy

[7] Broum, T.; Kopecky, M. \& Kleinova, J. (2010). Enhancement of Value Analysis using the Theory of Technical Systems, Annals of DAAAM for 2010 \& Proceedings of the 21st International DAAAM Symposium, ISSN 17269679, ISBN 978-3-901509-73-5, Editor B. Katalinic, pp 1121-1123, Published by DAAAM International, Vienna, Austria

[8] Gorner, T. \& Simon, M. (2015). Using the Theory of Technical Systems to Describe the Interaction between Human and Technical Systems within the Ergonomic System, Proceedings of the 25th DAAAM International Symposium, DAAAM 2014, ISSN: 18766102, Editor B[ranko] Katalinic, pp.592-601, Published by Elsevier Ltd., Vienna, Austria, DOI: 10.1016/j.proeng.2015.01.409

[9] Goerner, T.; Broum, T.; Simon, M. \& Kleinova, J. (2010). Use of Value Analysis to Increasing the Value of Ergonomic Design of Workplace, Annals of DAAAM for 2010 \& Proceedings of the 21st International DAAAM Symposium, ISSN 1726- 9679, ISBN 978-3-901509-73-5, Editor B[ranko] Katalinic, pp 1119-1120, Published by DAAAM International, Vienna, Austria

[10] Čechura, T.; Kamaryt, T. \& Kleinová, J. (2015). Innovative approach to supplying production, Proceedings of the 25th International Business Information Management Association Conference - Innovation Vision 2020, ISBN: 978098604194-5, Editor Soliman K.S, pp 495-504, Published by International Business Information Management Association, IBIMA, Amsterdam, Netherlands,

[11] Kamaryt, T. \& Kleinova, J. (2015). Handling equipment - The overall efficiency of supply processes, Proceedings of the 26th International Business Information Management Association Conference - Innovation Management and Sustainable Economic Competitive Advantage: From Regional Development to Global Growth, IBIMA 2015, ISBN: 978-098604195-2, Editor Soliman K.S, pp 2507-2515, Published by International Business Information Management Association, IBIMA, Madrid, Spain 